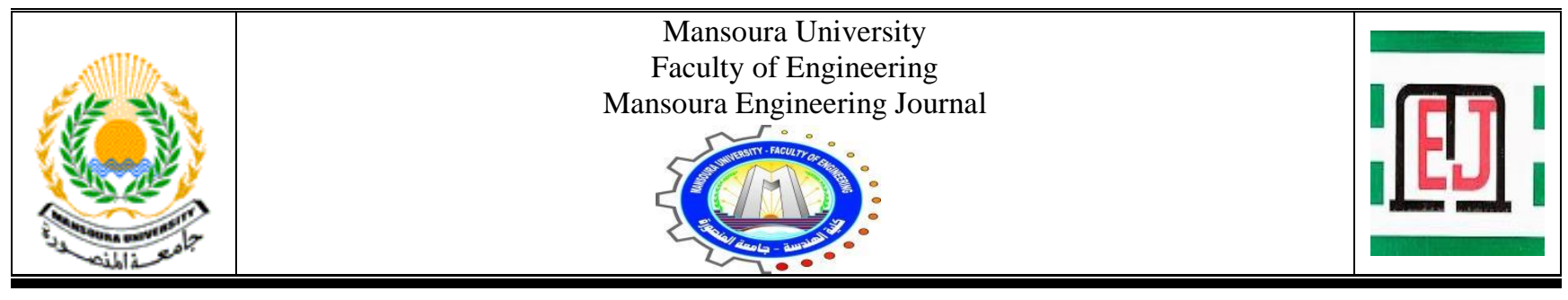

\title{
Assessment of Precise Point Positioning of Different Global Navigation Satellite Systems
}

\author{
Islam E. Ashour*, Mohamed E. El-Tokhey, Yasser M. Mogahed and Ahmed E. Ragheb
}

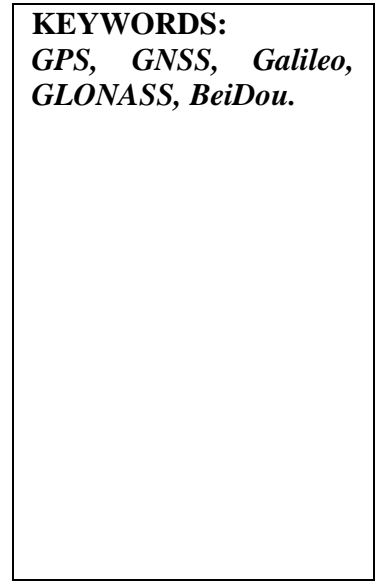

\begin{abstract}
With the accelerated development of multi constellation Global Navigation Satellite Systems (GNSS), the field of satellite navigation is going through profound changes. Depending on a single constellation may not be sufficient to guarantee a successful positioning accuracy at any time. Consequently, having several constellations that can be used for positioning offers the opportunity to maintain continuous positioning. This became possible with the global coverage of other constellations such as (BeiDou, GLONASS, Galileo, and GPS). For engineering and scientific applications, this will present both opportunities and obstacles. This paper develops a 4-system positioning model for all the available observations from other GNSS and benefits from them. The important enhancement of satellite visibility, precision dilution, spatial geometry, accuracy, convergence, continuity, and reliability that combined use of multi-GNSS achieve to accurate positioning is attentively inspected and assessed, particularly in strained environments, overall, in the horizontal and $10 \mathrm{~cm}$ vertical components with precise orbits the multi-GSS PPP has a precise accuracy greater than $4 \mathrm{~cm}$.
\end{abstract}

\section{INTRODUCTION}

$\mathrm{P}$ RECISE Point Positioning (PPP) is a technology, which has been developed about 15 years ago for accurate satellite positioning [1]. The main feature of the PPP approach is its capability to identify positions with high precision via only one dual-frequency GNSS receiver without communicating with a regional reference station or network.

Received: (25 July, 2021) - Revised: (02 September, 2021) - Accepted: (05 September, 2021)

Corresponding Author*: Islam E. Ashour, MSc Studen at Public worksFaculty of Engineering-Ain Shams university-Cairo - Egypt (e-mail: islam.ashour@eng.asu.edu.eg).

Mohamed E. El-Tokhey, Professor of Surveying and Geodesy, Public Works Department, Ain Shams University, Faculty of Engineering, Cairo, Egypt. (Email: meltoukhy@hotmail.com)

Yasser M. Mogahed, Associate professor of Surveying and Geodesy, Public Works Department, Ain Shams University, Faculty of Engineering, Cairo,Egypt. (Email: yasser_mogahed@eng.asu.edu.eg)

Ahmed E. Ragheb, Associate professor of Surveying and Geodesy, Public Works Department, Ain Shams University, Faculty of Engineering, Cairo, Egypt.(Email: aragheb@eng.asu.edu.eg)
This technique limits the demand to keep an expensive regional network of reference stations. Obtaining high accuracy of positioning is attainable because of the utilization of specific products International GNSS Service offered (IGS), such as the Earth Rotation parameters, Satellites Orbits accessed at intervals of 15 minutes, and Satellites Clocks with an interval of 30 seconds.

Moreover, many global navigation satellite systems (GNSS) PPP are another effective way of achieving higher accuracy and lower convergence periods through an increasing number of observations from several constellations [2]. Recently, multi-GNSS has gone through accelerated advancement, and several studies have illustrated its performance. The combined GPS and GLONASS PPP were first investigated because of the availability of GNSS satellites. The results showed a significant improvement in the convergence time of position, although the improvements rely heavily on the geometry of the visible satellite configuration. The results also indicate a minor increase in positioning accuracy because GLONASS satellites have limited availability [3]. PPP (Precise Point Positioning) model is currently being implemented with the co-existence of the four 
fully operated, independent Global Navigation Satellite Systems. These involve United States GPS (Global Positioning System), Chinese BeiDou (Big Dipper), Russian GLONASS, and the European Galileo. Each of these systems has the main task of independent estimation identification of coordinates of the points on the surface of the Earth and in its proximity. The main reason why new global satellite navigation systems are built is mainly because they can be independent from military GPS or can be reduced by accessibility to codes. [4]. The strength of satellite geometry can eliminate or suppress some errors and biases, as already known. One factor that helps to achieve good satellite geometry is the increase in the number of recipient satellites. In general, a larger number of received satellite signals leads to a better satellite [5]. In addition, the ability to simultaneously use multiple systems means:

- Increase the number of visible satellites, when satellite signals can be too low, in urban environments.

- Increasing the number of observations.

- Increasing the accuracy of the whole solution.

\section{MULTI-GNSS}

New services and signals have been presented recently with accelerated development of satellite technology and new and upgraded satellites. Most of the carrier phase and pseudorange data are available using civilian GNSS receivers. Back in 2007, Multi-constellation The precision GNSS (PPP) positioning was achieved with only two constellations, however: GLONASS and GPS. Having more satellites, accurate orbit, and clock products available from BeiDou and Galileo, it is now achievable to examine PPP with 4 constellations: BeiDou, GPS, Galileo, and GLONASS.

GPS has become the preferred tool of positioning for various applications, where greater accuracy such as structural monitoring in open air environments is required. Satellite availability and its geometry can affect the resulting position of GPS, the quality of observations with the ability to mitigation of most mistake sources, and the indexation of integer ambiguity for accurate positioning (Msaewe, et al. 2017). Operated by the US Department of Defense (DOD), GPS is the dominant, fully operational Global Navigation Satellite System. It is used for engineering, surveying, and geodetic applications, consisting at the moment of 32 Space Vehicles (SV) and transmitting microwave signals to be observed by GPS receivers to obtain their position relative to the worldwide WGS-84.

The Russian GLONASS has become the first alternative to GPS. In the mid-1970s of the 20th century, this system project was started. In 1982 the first satellite was started (Cosmos1413). GLONASS was originally developed by the former Union of Soviet Socialist Republics, and currently, the Russian government accounts for the system. A constellation of the GLONASS satellite comprises 27 satellites, including 23 operational satellites, $1 \mathrm{SV}$ in maintenance, $2 \mathrm{SV}$ in-flight tests phase, and 1spare SV (GLONASS status, 2021). The constellation consists of 24 operational satellites and was completed in 1995.

On the $11^{\text {th }}$ of February 2019, four additional Galileo satellites were operated, Nearly after the European global satellite navigation system constellation. First time ever, In terms of a high precision point positioning, it is possible to evaluate Galileo's performance (PPP) [6]. Currently, the Galileo constellation consists of 26 satellites, including 22 operational satellites, $3 \mathrm{SV}$ not usable, and $1 \mathrm{SV}$ not available (European Global Navigation Satellite Systems Agency, 2021).

By the end of 2012, China launched 16 Beidou2/Compass-2 navigation satellites. Basic navigation and precise pointing services capability have developed in the Asian-Pacific regions. To study the positioning performance and navigation of the Beidou-2 system [3], Wuhan University constructed a Beidou Experimental Tracking Station covering the world and extends the PANDA software to identify the orbits of Beidou satellites, which provide the Beidou satellites accurate orbit and satellite clock offset for users who need high precision positioning services. BeiDou constellation consists of 49 satellites, including 44 operational satellites and five not in operations (BeiDou status, 2021).

\section{Mathematical Model OF GNSS PPP}

GNSS Mathematical Models can also be displayed, considering the multi-GNSS observations, including GLONASS, GPS, BeiDou, and Galileo. [7].

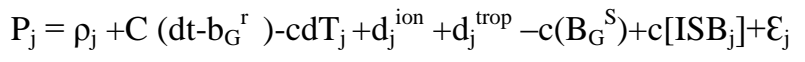

$\emptyset_{j}=\rho_{j}+C\left(d t-b_{G}{ }^{r}\right)-c d T_{j}-d_{j}^{\text {ion }}+d_{j}^{\text {trop }}-c\left(B_{j}{ }^{S}\right)+c\left[I S B_{j}\right]+\left[\lambda N_{j}+c\left(\delta j-d_{j}\right)-\right.$ $\left.\left(\delta_{\mathrm{j}}^{\mathrm{s}}-\mathrm{d}_{\mathrm{j}}^{\mathrm{s}}\right)\right]+\varepsilon_{\mathrm{j}}$

Where $\mathrm{j}$ is another global navigation system (GLONASS, Galileo, and Beidou); $\mathrm{dT}_{\mathrm{G}}$ and $\mathrm{dT}_{\mathrm{J}}$ are satellites clock error, for GPS and the other global navigation systems respectively, lumped with the ionosphere-free differential code bias, which can be obtained from the IGS-MGEX [8]; $\mathrm{d}^{\text {ion }}{ }_{1}$ is ionospheric delay in metres; $\mathrm{d}^{\text {trop }}{ }_{1}$ is the tropospheric meter-delay input; $\mathrm{B}_{\mathrm{G}}^{\mathrm{s}}$ and $\mathrm{B}_{\mathrm{J}}^{\mathrm{s}}$ are bias terms, which represent the combined action of differential satellite code bias for GPS and the other global navigation systems respectively.In comparison with the effects of other models, estimated TEC model is used for accounting for ionosphere retardation $\left(\mathrm{d}^{\text {ion }}{ }_{\mathrm{G}}\right.$ and $\left.\mathrm{d}_{\mathrm{J}}^{\mathrm{ion}}\right)$. The standard SFPPP algorithm in the estimation process is therefore considered as an unknown parameter.

The PPP technique enables the precision of statical positioning and decimetric or better for cinematic positioning to be achieved at a centimetre level. This high precision requires accurate modelling of measurements. This modeling considers the following terms:

- Precise satellite orbits and clocks: Rather than the transmitted ones used in the SPP, the precise orbits and clock files must be used. 
- Relativistic effects: Due to the orbital eccentricity considered in the SPP, the gravitation path correction can be added to the satellite clock correction.

- Atmospheric effects: The ionosphere refraction is eliminated with the ionosphere-free metering combinationt. The tropospheric refraction, where Niell mapping is used, can be modelled. The equation provides for the dry and wet troposphere delays. The deviation from the zenith tropospheric delay $\Delta \mathrm{T}_{z ; \text { wet }}$ in relation to the nominal $\mathrm{T}_{\mathrm{z0} \text {;wet }}$, along with coordinates, clock and phase biaises of the carrier should be estimated in Kalman's filter.

- Antenna biases and orientation: The GS ANTEX files after GPS Week 1400 can show satellite and receiver antenna phase centres.

- Ocean loading and pole tides: These are second-order effects and can be ignored at centimeter-level for PPP accuracies.

TABLE 1

. THE MEASUREMENT MODEL AND PARAMETERS ESTIMATION FOR MULTICONSTELLATION PPP

\begin{tabular}{l||l}
$\begin{array}{l}\text { Estimator } \\
\text { Observations }\end{array}$ & $\begin{array}{l}\text { All the Multi-GNSS observations are processed } \\
\text { together Raw carrier phase and pseudorange } \\
\text { observations; BeiDou, Galileo, GLONASS, and } \\
\text { GPS }\end{array}$ \\
\cline { 2 - 2 } \begin{tabular}{l|} 
Signal selection \\
Sampling rate
\end{tabular} & $\begin{array}{l}\text { GPS: L1/L2; GLONASS: L1/L2; BeiDou: } \\
\text { B1/Balileo: E1/E5a }\end{array}$ \\
\hline Elevation cutoff & $15 \mathrm{~s}$ \\
\hline Satellite orbit & Fixed \\
\hline Satellite clock & Fixed \\
\hline $\begin{array}{l}\text { Earth rotation } \\
\text { parameter }\end{array}$ & Fixed \\
\hline $\begin{array}{l}\text { Satellite antenna } \\
\text { phase center }\end{array}$ & Corrected using MGEX and IGS values \\
\hline $\begin{array}{l}\text { Receiver antenna } \\
\text { phase center }\end{array}$ & Corrected \\
\hline Troposphere & Saastamoinen model \\
\hline Ionosphere & Ionosphere-free linear combination \\
\hline $\begin{array}{l}\text { System } \\
\text { monitoring }\end{array}$ & Static
\end{tabular}

\section{EXPERIMENTS DESCRIPTION}

To study the accuracy of using each constellation individually and Integrating GNSS, multi-constellations oneday datasets were collected at SHMS station in Egypt at Cairo on 25 May 2019. Also, multi-constellations 24 hours datasets were collected at Monib station on 24 May 2019. Such data sets are used to evaluate the PPP performance, and a flow chart summarizes the convergence time (figure 1) depending on broadcast and precise orbits, respectively. Trimble-NET9 was mounted on a permanent SHMS station at the top of the main building at the Faculty of Engineering Ain Shams University [9], and Trimble R8S antennas were mounted on the top of the building at Monib station. (As shown in Figure 2).

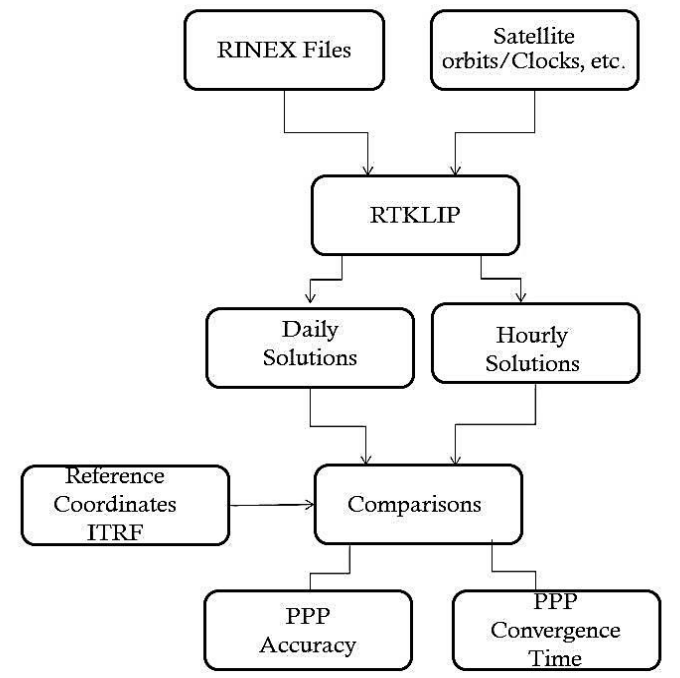

Figure 1. Flow chart for the PPP processing and assessment of the PPP accuracy and convergence time

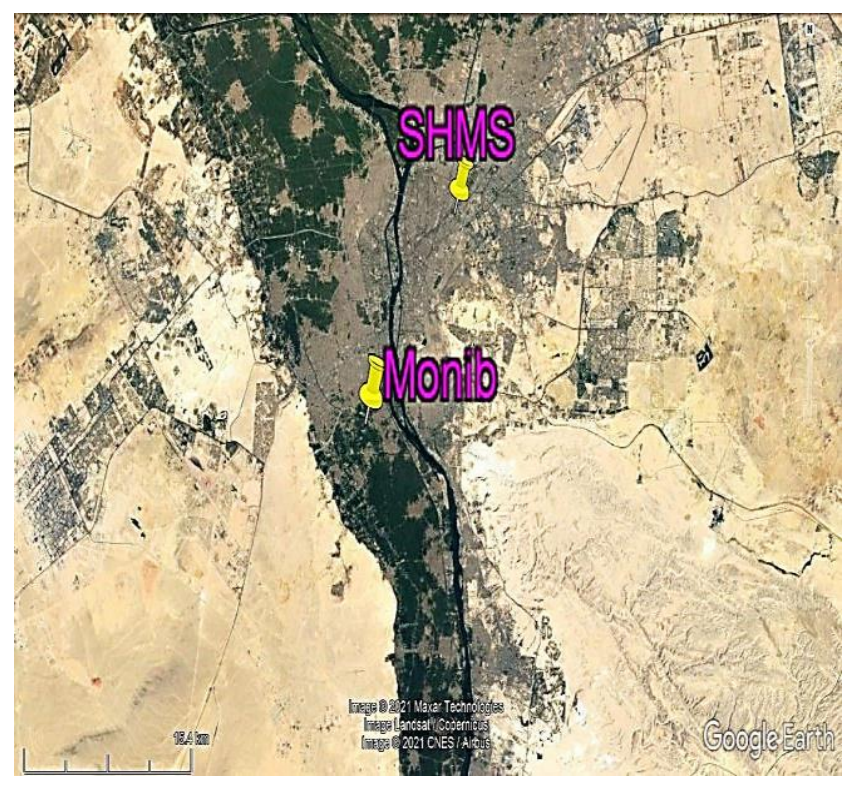

Figure 2. Locations of the selected stations (Google Earth, Cairo, Egypt)

\section{TEST MEASUREMENTS}

The obtained GNSS observations were processed using the RTKLIB version 2.3 [10] with a duration length of 24-hour. GNSS observations were recorded with a 15 -second epoch interval in a static mode for multiple signals and with 10 degrees cutting off-angle (as shown in Table 1). After completing all of the observations, the data of observations is downloaded and then is processed with five solutions for 24 hours, respectively:

- solution I- measurements based on GPS;

- solution II - measurements based on GLONASS;

- solution III - measurements based on Galileo;

- solution IV - measurements based on BeiDou;

- solution V - combined solution (measurements based on GPS, GLONASS, Galileo, and BeiDou). 
For example, in the four-system station SHMS, the visibilities of satellite for Galileo, GLONASS, BeiDou, and GPS on $25^{\text {th }}$ of May 2019, are illustrated in table 2. It is clear that joint use of different GNSS brings great enhancements in satellite visibility. It is also clear that the visibility varies greatly for different orbital types.

Table 2.

Position Dilution of Precision (PDOP) and visible satellites during measurements

\begin{tabular}{l||l||l||l||l}
\multirow{2}{*}{\multicolumn{1}{c||}{ Solution }} & \multicolumn{3}{c||}{ 24-hr/PDOP } & $\begin{array}{c}\text { The number of } \\
\text { visible satellites }\end{array}$ \\
\cline { 2 - 3 } & MIN & MAX & AVG & \\
\hline Solution I & 1.5 & 3.5 & 2.5 & 31 \\
\hline Solution II & 1.2 & 4.5 & 3.45 & 22 \\
\hline Solution III & 1.6 & 3.9 & 2.75 & 24 \\
\hline Solution IV & 2.1 & 7.1 & 4.6 & 10 \\
\hline Solution $V$ & 0.8 & 0.95 & 0.9 & 71
\end{tabular}

From Table 2, although the GPS solution has the best configuration maximum number of visible satellites and Minimum PDOP, the differences between each individual system (Solution II, III, and IV) and the GPS solution are small. Galileo's configuration (solution III) is better than the configuration of BeiDou and GLONASS.

Based on the above methods, we process one day's data, $25^{\text {th }}$ of May 2019 at SHMS station and one day, $24^{\text {th }}$ of May 2019 at Monib station, using the RTKLIB version 2.3 Package in Software modes GPS, GLONASS, Galileo, Beidou, and GPS+GLONASS+Galileo+Beidou static PPP and analyzing the precisions of the positioning results using broadcast and precise orbits, respectively.

Table 3

Positional errors of Static PPP solutions of single-system (GPS, GLONASS, Galileo, and BDS), and combined-system (GPS+GLONASS+Galileo+BDS) at station SHMS on May 25, 2019, using broadcast orbits.

\begin{tabular}{|c|c|c|c|c|}
\hline statistics & Max. & Min. & S.D & \\
\hline$E(m)$ & 0.18 & -0.39 & 0.14 & \multirow{3}{*}{ GPS } \\
\hline$N(m)$ & 0.15 & -1.00 & 0.17 & \\
\hline$H(m)$ & 5.50 & -0.96 & 0.72 & \\
\hline$E(m)$ & 1.10 & -2.96 & 1.61 & \multirow{3}{*}{ GLONASS } \\
\hline$N(m)$ & 0.57 & -1.58 & 0.32 & \\
\hline$H(m)$ & 1.20 & -4.30 & 0.69 & \\
\hline$E(m)$ & 0.35 & -0.53 & 0.35 & \multirow{3}{*}{ Galileo } \\
\hline$N(m)$ & 0.30 & -0.20 & 0.41 & \\
\hline$H(m)$ & 0.93 & -0.70 & 0.57 & \\
\hline$E(m)$ & 11.02 & 4.80 & 5.16 & \multirow{3}{*}{ BDS } \\
\hline$N(m)$ & 2.13 & -6.00 & 1.67 & \\
\hline$H(m)$ & 5.16 & 1.67 & 5.80 & \\
\hline$E(m)$ & 0.28 & -1.17 & 0.30 & \multirow{3}{*}{$\begin{array}{l}\text { Combined } \\
\text { Solution }\end{array}$} \\
\hline$N(m)$ & 0.11 & -1.07 & 0.32 & \\
\hline$H(m)$ & 0.98 & -1.02 & 0.56 & \\
\hline
\end{tabular}

Reference coordinates are in the ITRF08, at epoch DOY: 145/2019
Table 4

.Positional errors of Static PPP solutions of single-system (GPS, GLONASS, Galileo, and BDS), and combined-system (GPS+GLONASS+Galileo+BDS) at station Monib on May 24, 2019, using broadcast orbits.

\begin{tabular}{|c|c|c|c|c|}
\hline statistics & Max. & Min. & S.D & \\
\hline$E(m)$ & 0.19 & -0.38 & 0.145 & \multirow{3}{*}{ GPS } \\
\hline$N(m)$ & 0.162 & -1.11 & 0.172 & \\
\hline$H(m)$ & 5.471 & -0.96 & 0.715 & \\
\hline$E(m)$ & 1.08 & -2.94 & 1.625 & \multirow{3}{*}{ GLONASS } \\
\hline$N(m)$ & 0.561 & -1.57 & 0.31 & \\
\hline$H(m)$ & 1.21 & -4.5 & 0.69 & \\
\hline$E(m)$ & 0.34 & -0.53 & 0.349 & \multirow{3}{*}{ Galileo } \\
\hline$N(m)$ & 0.29 & -0.213 & 0.403 & \\
\hline$H(m)$ & 0.94 & -0.68 & 0.562 & \\
\hline$E(m)$ & 11.3 & 4.9 & 5.12 & \multirow{3}{*}{ BDS } \\
\hline$N(m)$ & 2.12 & -6 & 1.69 & \\
\hline$H(m)$ & 5.15 & 1.65 & 5.755 & \\
\hline$E(m)$ & 0.282 & -1.175 & 0.32 & \multirow{3}{*}{$\begin{array}{l}\text { Combined } \\
\text { Solution }\end{array}$} \\
\hline$N(m)$ & 0.12 & -1.8 & 0.33 & \\
\hline$H(m)$ & 0.995 & -1.15 & 0.565 & \\
\hline
\end{tabular}

Reference coordinates are in the ITRF08, at epoch DOY: 144/2019

Tables 3 and 4 show static positional errors of PPP solutions of SHMS and Monib stations using broadcast orbits. After rejecting high DOP observations, the combined system and Galileo-only positioning performance are better than the GPS-only and GLONASS-only. The BeiDou PPP exhibits poor performance than the other system.

Table 5 .

Positional errors of Static PPP solutions of single-system (GPS, GLONASS, Galileo, and BDS), and three-system (GPS+GLONASS+Galileo+BDS) at station SHMS on May 25, 2019, using precise orbits.

\begin{tabular}{|c|c|c|c|c|}
\hline statistics & Max. & Min. & S.D & \\
\hline$E(m)$ & 0.16 & -0.39 & 0.11 & \multirow{3}{*}{ GPS } \\
\hline$N(m)$ & 0.11 & -0.61 & 0.06 & \\
\hline$H(m)$ & 2.20 & 0.23 & 0.30 & \\
\hline$E(m)$ & 0.43 & -0.09 & 0.11 & \multirow{3}{*}{ GLONASS } \\
\hline$N(m)$ & 0.62 & -0.04 & 0.08 & \\
\hline$H(m)$ & -2.00 & -0.03 & 0.18 & \\
\hline$E(m)$ & 0.04 & -0.10 & 0.04 & \multirow{3}{*}{ Galileo } \\
\hline$N(m)$ & 0.19 & -0.10 & 0.03 & \\
\hline$H(m)$ & 0.09 & -0.50 & 0.11 & \\
\hline$E(m)$ & 4.20 & -1.20 & 1.75 & \multirow{3}{*}{ BDS } \\
\hline$N(m)$ & 1.70 & -0.50 & 0.55 & \\
\hline$H(m)$ & 4.30 & -2.20 & 1.17 & \\
\hline$E(m)$ & 0.13 & -0.02 & 0.04 & \multirow{3}{*}{$\begin{array}{l}\text { Combined } \\
\text { Solution }\end{array}$} \\
\hline$N(m)$ & 0.19 & -0.04 & 0.03 & \\
\hline$H(m)$ & 0.18 & -0.70 & 0.12 & \\
\hline
\end{tabular}

Reference coordinates are in the ITRF08, at epoch DOY: 145/2019 
Table 6.

Positional errors of Static PPP solutions of single-system (GPS, GLONASS, Galileo, and BDS), and three-system (GPS+GLONASS+Galileo+BDS) at station Monib on May 24, 2019, using precise orbits.

\begin{tabular}{|c|c|c|c|c|}
\hline statistics & Max. & Min. & S.D & \\
\hline$E(m)$ & 0.162 & -0.39 & 0.12 & \multirow{3}{*}{ GPS } \\
\hline$N(m)$ & 0.13 & -0.64 & 0.07 & \\
\hline$H(m)$ & 2.22 & 0.215 & 0.33 & \\
\hline$E(m)$ & 0.45 & -0.12 & 0.15 & \multirow{3}{*}{ GLONASS } \\
\hline$N(m)$ & 0.63 & -0.06 & 0.083 & \\
\hline$H(m)$ & -2.02 & -0.05 & 0.181 & \\
\hline$E(m)$ & 0.038 & -0.12 & 0.043 & \multirow{3}{*}{ Galileo } \\
\hline$N(m)$ & 0.21 & -0.15 & 0.04 & \\
\hline$H(m)$ & 0.095 & -0.51 & 0.12 & \\
\hline$E(m)$ & 4.3 & -1.25 & 1.79 & \multirow{3}{*}{ BDS } \\
\hline$N(m)$ & 1.73 & -0.523 & 0.561 & \\
\hline$H(m)$ & 4.35 & -2.221 & 1.18 & \\
\hline$E(m)$ & 0.145 & -0.03 & 0.05 & \multirow{3}{*}{$\begin{array}{l}\text { Combined } \\
\text { Solution }\end{array}$} \\
\hline$N(m)$ & 0.25 & -0.06 & 0.04 & \\
\hline$H(m)$ & 0.19 & -0.75 & 0.13 & \\
\hline
\end{tabular}

Reference coordinates are in the ITRF08, at epoch DOY: 144/2019

Tables 5 and 6 shows SHMS and Monib stations' static PPP solutions using accurate orbits. For the GPS-only solution, a positioning precision of $1 \mathrm{dm}$ can be improved. After a sufficient time of convergence, GLONASS positioning accuracy is also less than GPS solutions. A BeiDou-only PPP solution cannot be extracted at these stations, as there are not adequate satellites that can be observed. The combined system and Galileo PPP also demonstrate the quickest convergence, the most balanced position series, and the highest precision in all 3 components, it is noticed that positioning accuracy is significantly improved in addition to the increase in the observational length.

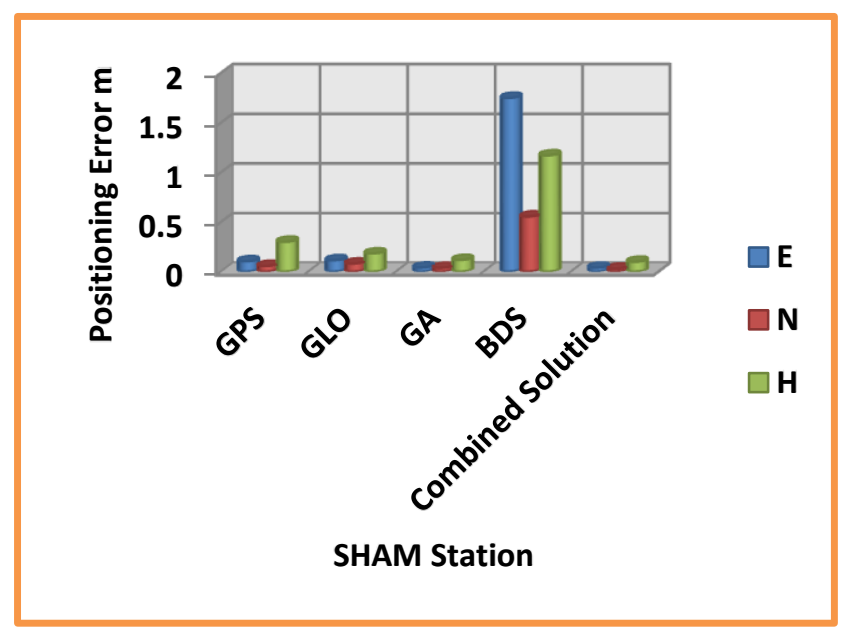

Figure 3. RMS for Easting, Northing, and Height for SHMS Station and using precise orbits.

Figure 3 shows Static PPP solutions statistical results. From all static PPP solutions, the root means square (RMS) calculation of values. It can be noted that. With the same session length, The combined system can achieve the highest precision with the only PPP of Galileo. In comparison with only GPS and GLONASS, also the system combined with Galileo-only PPP significantly improves the PPP performance.
More than the eastern and vertical components, positioning accuracy in the northerly part is general better (maybe because of the satellite constellation configuration).

Six-hr-day sessions at 2 hours, 4 hours, 6 hours, 8 hours, 12 hours, 24 hours at DOY: 145/2019 at the SHMS station will be held to assess the convergence time performance of the PPP.

Table 7

The RMS for Easting, Northing, and Height components in meters for the PPP hourly solutions at the SHMS station

\begin{tabular}{|c|c|c|c|c|c|c|c|}
\hline statistics & $2 \mathrm{~h}$ & $4 \mathrm{~h}$ & $6 \mathrm{~h}$ & $8 \mathrm{~h}$ & $12 \mathrm{~h}$ & $24 \mathrm{~h}$ & \\
\hline$E(m)$ & 0.24 & 0.24 & 0.21 & 0.19 & 0.16 & 0.11 & \multirow{3}{*}{ GPS } \\
\hline$N(m)$ & 0.25 & 0.20 & 0.17 & 0.15 & 0.12 & 0.06 & \\
\hline$H(m)$ & 0.58 & 0.44 & 0.36 & 0.31 & 0.26 & 0.30 & \\
\hline$E(m)$ & 0.39 & 0.39 & 0.44 & 0.44 & 0.40 & 0.11 & \multirow{3}{*}{ GLONASS } \\
\hline$N(m)$ & 0.08 & 0.07 & 0.06 & 0.05 & 0.04 & 0.08 & \\
\hline$H(m)$ & 0.47 & 0.43 & 0.39 & 0.35 & 0.31 & 0.18 & \\
\hline$E(m)$ & 0.05 & 0.04 & 0.04 & 0.05 & 0.04 & 0.04 & \multirow{3}{*}{ Galileo } \\
\hline$N(m)$ & 0.18 & 0.14 & 0.11 & 0.10 & 0.08 & 0.04 & \\
\hline$H(m)$ & 0.19 & 0.19 & 0.19 & 0.18 & 0.16 & 0.12 & \\
\hline$E(m)$ & 2.42 & 2.41 & 2.70 & 2.73 & 2.29 & 1.75 & \multirow{3}{*}{ BDS } \\
\hline$N(m)$ & 0.94 & 0.92 & 0.97 & 0.91 & 0.80 & 0.06 & \\
\hline$H(m)$ & 2.29 & 2.27 & 2.41 & 2.36 & 1.93 & 1.17 & \\
\hline$E(m)$ & 0.06 & 0.06 & 0.06 & 0.05 & 0.04 & 0.04 & \multirow{3}{*}{$\begin{array}{l}\text { Combined } \\
\text { Solution }\end{array}$} \\
\hline$N(m)$ & 0.15 & 0.12 & 0.10 & 0.09 & 0.07 & 0.03 & \\
\hline$H(m)$ & 0.16 & 0.22 & 0.19 & 0.17 & 0.15 & 0.10 & \\
\hline
\end{tabular}

Reference coordinates are in the ITRF08, at epoch DOY: 145/2019

From Table 7, The main results obtained by investigations of the hourly session solutions are as follows: (a) A combined system with a convergence time of $2 \mathrm{~h}$ for the east, north and high, respectively, provides less than $6 \mathrm{~cm}, 15 \mathrm{~cm}$, and $16 \mathrm{~cm}$ accuracy. (b) Galileo can achieve the highest accuracy compared to GPS-only and GLONASS-only with accuracy less than $5 \mathrm{~cm}, 18 \mathrm{~cm}$, and $19 \mathrm{~cm}$ accuracy with a convergence time of $2 \mathrm{~h}$ for the east, north, and height, respectively. (c) BeiDou can achieve the worst accuracy compared to other systems with $2 \mathrm{~h}$ for east, north and height convergence time, respectively.

\section{CONCLUSION}

BeiDou PPP displays poorer performance than the GPSonly PPP because of the uncertainty of BDS accurate orbits and clock solutions at the level of decimeters. Mainly, this is because the BeiDou has a few Satellites. Also, the combined system and Galileo-only positioning performance are better than the GPS-only and GLONASS-only. In addition, it is noted that the results of the combined system give the best performance in the studying area, which is covered by the current Galileo service. Overall, in the horizontal and $10 \mathrm{~cm}$ vertical components with precise orbits the multi-GSS PPP has a precise accuracy greater than $4 \mathrm{~cm}$.

\section{AUTHORS CONTRIBUTION}

Conception or design of the work (Mohamed E. El-Tokhey) Data collection and tools (Islam E. Ashour)

Data analysis and interpretation (Islam E. Ashour, Mohamed E. El-Tokhey, Ahmed E. Ragheb) 
Funding acquisition (Islam E. Ashour)

Investigation (Islam E. Ashour, Yasser M. Mogahed, Ahmed E. Ragheb)

Methodology (Islam E. Ashour, Yasser M. Mogahed, Ahmed E. Ragheb)

Project administration (Islam E. Ashour, Mohamed E. El-

Tokhey, Yasser M. Mogahed and Ahmed E. Ragheb)

Resources (Islam E. Ashour, Mohamed E. El-Tokhey)

Software (Islam E. Ashour, Mohamed E. El-Tokhey)

Supervision (Islam E. Ashour, Mohamed E. El-Tokhey,

Ahmed E. Ragheb)

Drafting the article (Islam E. Ashour, Mohamed E. El-

Tokhey, Ahmed E. Ragheb)

Critical revision of the article. (Islam E. Ashour, Ahmed E. Ragheb)

Final approval of the version to be published (Islam E. Ashour, Ahmed E. Ragheb)

All authors have read and agreed to the published version of the manuscript.

\section{REFERENCES}

\section{BIBLIOGRAPHY}

[1] Y. Gao, "Development of a real-time single-frequency precise point positioning system and test results," Proceedings of ION GNSS 2006, p. 2297-2303, Sept 2006.

[2] M. Ge, G. Gendt, M. Rothacher, C. Shi, and J. Liu, "Resolution of GPS carrier-phase ambiguities in Precise Point Positioning (PPP) with daily observations," Geod, p. 389-399, 2008.

[3] C. Cai and Y. Gao, "Performance Analysis of Precise Point Positioning Based on Combined GPS and GLONASS," in Fort Worth Convention Center: Fort Worth, TX, USA, 2007.

[4] Z. Siejka, "Multi-GNSS As A Combination Of GPS, Glonass And Beidou Measurements Carried Out In Real Time," ARTIFICIAL SATELLITES, vol. 50, no. 4-2015, pp. 217-229, 2015.

[5] K. I. M. Anjasmara, D. G. Pratomo, and W. Ristanto, "ACCURACY ANALYSIS OF GNSS (GPS, GLONASS, AND BEIDOU) OBSERVATION FOR POSITIONING," in E3S Web of Conferences 94, Surabaya, Indonesia, 2019.
[6] G. Katsigianni, F. Perosanz, S. Loyer and M. Gupta, "Galileo millimeterlevel kinematic precise point positioning with ambiguity resolution," 2019.

[7] M. Abd Rabbou. and A. El-Rabbany, "Multi-Constellation GNSS Single frequency PPP: An Efficient Technique for Low-Cost Surveying Applications," Research poster, the Association of Ontario Land Surveyors, 26 February 2015.

[8] O. Montenbruck, P. Steigenberger, R. Khachikyan, G. Weber, R. Langley, L. Mervart and U. Hugentobler, IGS-MGEX: Preparing the Ground for Multi-Constellation GNSS Science, Prague: 4th Int. Colloquium on Scientific and Fundamental Aspects of the Galileo System, 2014.

[9] M. El-Tokhey, Y. M. Mogahed, M. Mamdouh and T. W. Hassan , "Establishment of New Continuous Operating Reference Station (CORS) at Faculty of Engineering, Ain Shams University," International Journal of Engineering and Advanced Technology (IJEAT), vol. 7, no. 4, 2018.

[10] T. Takasu, "RTKLIB: Open Source Program Package for RTK-GPS," FOSS4G 2009 Tokyo, 2009.

\section{Title Arabic:}

تقييم دقة تحديد المواقع لأنظمة الأقمار الملاحية العالمية المختلفة

\section{Arabic Abstract:}

مع التطور السريع لأنظمة الأقمار الملاحية العالمية ، يمر مجال الملاحة عبر الأقمار

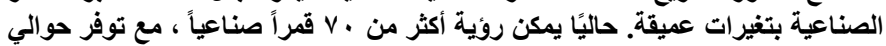

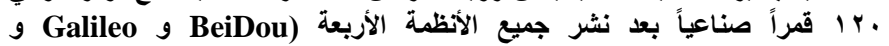

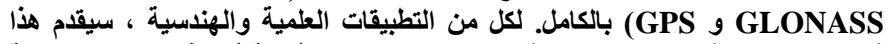

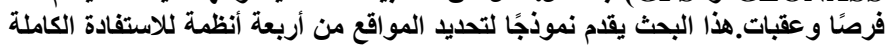

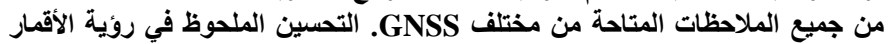

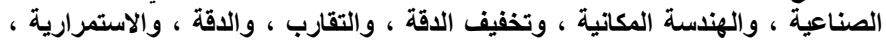

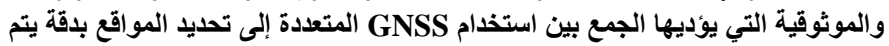

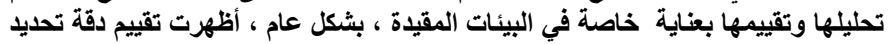

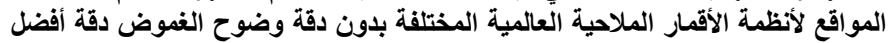

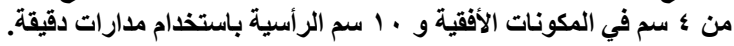

